\title{
Strategi Pemasaran Digital Pariwisata Berbasis Budaya Pemerintah Kota Surakarta (Studi Kasus Batik Solo TV di Instagram)
}

\author{
Ivanovich Aldino \\ Institut Seni Indonesia Yogyakarta; \\ Jl. Parangtritis KM.6, RW.5, Glondong, Panggungharjo, \\ Kec. Sewon, Bantul, Daerah Istimewa Yogyakarta 55188 \\ E-mail: ivanovich.aldino@gmail.com
}

\begin{abstract}
ABSTRAK
Penelitian ilmiah terkait promosi digital dalam bidang pariwisata kota dibutuhkan untuk memberikan edukasi pentingnya perancangan sistem promosi di era digital. Studi kasus pada Batik Solo TV ini membahas dan menganalisis berbagai faktor yang memengaruhi capaian konten promosi digital yang diunggah akun resmi Pemerintah Kota Surakarta dalam platform media sosial. Rumusan penelitian ini mengulas strategi yang dilakukan pengelola Solo Batik TV dalam merancang konten dan bekerja sama dengan pengelola event kebudayaan di Kota Surakarta. Penelitian ini juga menguji konten promosi digital Solo Batik TV dengan sudut pandang follower akun media sosial pemerintah kota. Penulis menggunakan metode penelitian deskriptif kualitatif dengan pendekatan studi kasus, bertujuan mengetahui teknik penerapan konten audio visual untuk meningkatkan hasil capaian dari kegiatan kebudayaan Kota Surakarta. Penelitian ini menunjukkan bagaimana pengelola Solo Batik TV mengelola konten promosi digital wisata kota. Sehingga hasil penelitian bisa memberikan pandangan baru dalam implementasi manajemen khususnya pada bidang pengelolaan konten audio visual untuk promosi digital wisata kota.
\end{abstract}

Kata kunci: pemasaran digital, manajemen konten audio visual, manajemen sosial media, solo batik TV

Tourism Digital Marketing Strategy Based on the Culture

of the Surakarta City Government (Case Study Batik Solo TV on Instagram)

ABSTRACT

Scientific research in digital promotion for city tourism is paramount to educate the importance of promotion system design in the digital era. A case studies Solo Batik TV analyzing and discussing factors concerning achieved digital promotion content uploaded by official Surakarta's Government account on the social media platform. This research reviews strategy used by Solo Batik TV management in designing content and collaboration with other cultural affairs agencies in Surakarta. This thesis also tested Solo Batik TV digital promotion content from the city's social media follower perspective. The researcher used a qualitative descriptive research method with a case study approach to better understand the usage of audiovisual content to increase performance from cultural events in Surakarta. This research shows how Solo Batik TV manages the city's digital promotion content. This research aims to give a new perspective in the management implementation, notably in the audiovisual content management for city digital tourism promotion.

Keywords: digital marketing. audio visual content management, social media management, solo batik TV 


\section{PENDAHULUAN}

Pada era globalisasi dan digital seperti saat ini, muncul gejala berupa pergeseran strategi pemasaran produk. Perubahaan ini berjalan sangat cepat seiring dengan kemajuan zaman. Pergeseran strategi pemasaran tidak hanya berhenti memengaruhi penjualan barang akan tetapi mulai merambah ke produk seni budaya. Salah satunya ialah produk seni budaya yang berbentuk kegiatan festival berbasis budaya. Indonesia sendiri sangat terkenal akan keberagaman produk kesenian dan kebudayaannya. Produk budaya menjadi daya tarik tersendiri yang mampu menarik minat penonton untuk datang menyaksikan. Oleh karena itu, keberagaman jenis produk kebudayaan tersebut mulai dilirik menjadi salah satu potensi yang dapat dikembangkan untuk menunjang sektor pariwisata. Potensi seni budaya unggulan dikemas dengan satu rangkaian yang bertema festival.

Kegiatan pariwisata berbasis budaya banyak dikembangkan di kota-kota besar seperti Jember, DKI Jakarta, D.I. Yogyakarta, hingga Surakarta. Surakarta menjadi salah satu kota dengan kalender event tahunan yang menampilkan banyak kegiatan pariwisata berbasis budaya seperti festival, karnaval, pertunjukan musik dan tari yang mengangkat beragam potensi seni budaya yang berkembang di Kota Bengawan. Mulai dari festival untuk anak-anak yang dikemas dengan Festival Dolanan Bocah, Festival Payung, hingga festival dengan mengangkat satu tema atau genre khusus seperti Festival Keroncong. Kehadiran beragam pariwisata berbasis budaya di Surakarta menjadi daya tarik tersendiri bagi wisatawan, baik domestik maupun mancanegara, hadir menyaksikan perhelatan akbar yang digelar setiap tahunnya.

Pemasaran sebuah produk kebudayaan pada awalnya banyak menggunakan ilustrasi visual dalam bentuk poster, baliho, hingga papan iklan yang terletak di titik-titik strategis kota. Seiring perkembangan teknologi dan akses komunikasi mudah melalui internet, peranan audio visual menjadi salah satu sarana pemasaran yang diperhitungkan. Audio visual menjadi sarana penting dalam memasarkan produk kebudayaan karena lebih mudah dipahami oleh banyak kalangan dan dapat menjangkau area yang lebih luas saat dikombinasikan dengan internet. Penggunaan internet dalam berbagai bidang di Indonesia mengalami peningkatan pesat dari tahun ke tahun. Salah satu media sosial favorit masyarakat Indonesia yang tumbuh dengan cepat adalah Instagram. Dalam waktu kurang dari satu tahun, pengguna akun media sosial ini telah bertambah sebanyak seratus juta pengguna di seluruh dunia. Salah satu platform yang tinggi digunakan masyarakat Indonesia adalah Instagram (Bohang-Kompas.com, 2018) Selain pertumbuhan pengguna yang tinggi, Instagram juga memiliki keunggulan konten yang mudah karena terbatas pada foto dan audio visual, sehingga untuk produksi konten, Instagram lebih mudah dan admin bisa dengan mudah mengunggah konten yang stoknya telah banyak dipersiapkan oleh Batik Solo TV. 
Meskipun audio visual menjadi sarana pemasaran yang potensial tetapi produk audio visual harus direncanakan dengan konsep sebaik mungkin agar mampu merepresentasikan rancangan sebuah kegiatan pariwisata berbasis budaya. Perencanaan produksi dan pengelolaan konten audio visual ini merupakan salah satu rangkaian dari kegiatan promosi. Konten Batik Solo TV secara estetika visual sudah terlihat bagus akan tetapi masalah berikutnya jumlah penonton yang masih minim. Kondisi tersebut menjadi indikator diperlukannya perancangan strategi yang baik. Tayangan audio visual dari beragam kegiatan kebudayaan berdurasi satu menit tersebut menjadi media pemasaran baru yang memperkuat branding pariwisata kota.

\section{METODE PENELITIAN}

\section{a. Lingkup Penelitian}

1. Lokasi Penelitian

Penelitian dilakukan di Kota Surakarta, Jawa Tengah. Kota Surakarta terletak antara $110^{\circ} 45^{\prime} 15^{\prime \prime}$ dan $110^{\circ} 45^{\prime} 35^{\prime}$ ' Bujur Timur dan antara $7^{\circ} 36^{\prime}$ dan $7^{\circ} 56^{\prime}$ Lintang Selatan. Wilayah Kota Surakarta atau lebih dikenal dengan "Kota Solo" merupakan dataran rendah dengan ketinggian $\pm 92 \mathrm{~m}$ dari permukaan laut.

Luas wilayah Kota Surakarta adalah 44,06 $\mathrm{Km}^{2}$ dan secara administrasi terbagi menjadi lima wilayah administrasi kecamatan, 51 kelurahan, 602 Rukun Warga (RW), dan 2.708 Rukun Tetangga (RT).

2. Objek Penelitian

Objek penelitian yaitu konten audio visual yang diproduksi oleh Batik Solo TV yang dikelola Dinas Komunikasi dan Informasi Kota Surakarta. Pemilihan objek ini memiliki alasan latar belakang yang kuat untuk dijadikan penelitian. Menjadi pertimbangan, dengan melihat Batik Solo TV merupakan salah satu bentuk kemajuan promosi digital yang dimulai oleh level pemerintah daerah yang belum banyak dikembangkan daerah lain di Indonesia. Batik Solo TV menjadi salah satu pionir bentuk promosi digital di tataran pemerintah daerah.

3. Subjek Penelitian

Pemilihan narasumber dalam penelitian ini ditentukan oleh pengetahuan tentang Batik Solo TV, kontribusi terhadap Batik Solo TV, keterlibatannya dengan Batik Solo TV, yang berperan penting dalam terlaksananya sistem promosi digital Pemerintah Daerah Surakarta.

\section{b. Jenis Penelitian}

Penelitian dalam karya tulis ilmiah ini bersifat deskriptif kualitatif dengan tujuan mengetahui teknik pengelolaan konten audio visual untuk meningkatkan hasil capaian dari pemasaran digital pariwisata berbasis budaya Kota Surakarta. 
Data yang berupa analisis dari konten media sosial dan terkait kebijakan pengelola tidak akan bisa kita paparkan melalui angka-angka, oleh sebab itu, jenis penelitian deskriptif kualitatif dirasa paling relevan untuk mengupas objek penelitian tersebut.

\section{c. Jenis dan Sumber Data}

Sumber data yang digunakan kali ini ada dua, yaitu: Data Primer sebagai data utama dan Data Sekunder sebagai data pendukung untuk memperkuat dan melengkapi penelitian.

1. Data Primer: merupakan data yang diperoleh secara langsung dari sumber data melalui pengamatan dan wawancara kepada pengelola kegiatan kebudayaan yang digelar dalam kurun waktu tahun 2018 yang merepresentasikan untuk branding Kota Surakarta sebagai Kota Budaya, Pengelola Batik Solo TV di bawah Dinas Komunikasi dan Informasi Kota Surakarta. Pengelola yang dimaksud adalah pengelola konten audio visual dalam hal ini admin Instagram Pemerintah Kota.

2. Data Sekunder: merupakan data pendukung yang digunakan sebagai penunjang dalam penelitian setelah data primer. Data tersebut dikumpulkan dari berbagai artikel dan studi literatur. Data sekunder meliputi buku-buku dan artikel internet yang mengulas tentang pemasaran digital dan manajemen event.

\section{d. Teknik Pengumpulan Data}

\section{Observasi Tak Berperan}

Karena objek penelitian berupa kegiatan kebudayaan yang digelar oleh Dinas Kebudayaan dan Pariwisata (Disbudpar) Kota Surakarta, maka observasi yang dilakukan adalah observasi tak berperan, yaitu penulis dalam melakukan penelitian tidak terlibat langsung terhadap objek yang diteliti (Sutopo, 2006: 75). Dalam hal ini penulis hanya berperan sebagai pengamat tanpa memberikan pengaruh apapun pada objek yang diteliti.

2. Wawancara/Pertanyaan Terbuka

Wawancara dengan pertanyaan terbuka ditujukan kepada narasumber sebagai individu yang memahami penerapan sistem manajemen promosi digital di media sosial Pemerintah Kota Surakarta, sehingga yang dinyatakan oleh narasumber dapat diyakini sebagai kebenaran dan dapat dipercaya. Teknik wawancara menggunakan panduan semi terstruktur, dalam artian pertanyaan yang sudah disusun dapat dimodifikasi urutan serta kalimatnya sesuai dengan alur pembahasan dalam proses wawancara.

\section{Studi Pustaka}

Studi pustaka merupakan salah satu upaya guna memperoleh data dan informasi yang berkaitan dengan objek penelitian dengan cara mempelajari berbagai literatur. Studi pustaka digunakan untuk menggali data tentang pengelolaan kegiatan kebudayaan. 


\section{e. Variabel}

Dalam penelitian ini variabel yang digunakan adalah variabel yang termasuk dalam faktor internal yang dibagi menjadi Kekuatan dan Kelemahan, dan faktor eksternal yang dibagi menjadi Peluang dan Ancaman. Berikut ini variabel yang digunakan dalam penelitian ini dan daftar panduan pertanyaan (terlampir) yang tersaji pada Tabel 1 .

Tabel 1. Variabel Internal dan Eksternal

\begin{tabular}{|c|c|}
\hline ANALISIS & VARIABEL \\
\hline Faktor Internal & $\begin{array}{l}\text { Kekuatan } \\
\text { 1. Pemerintah Kota Surakarta mengembangkan sistem } \\
\text { pemasaran digital untuk pariwisata tingkat pemerintah } \\
\text { daerah. } \\
\text { 2. Pemasaran digital pariwisata dengan media sosial } \\
\text { mempermudah akses informasi untuk masyarakat. } \\
\text { 3. Keunikan konten dalam bentuk audio visual melalui video } \\
\text { kreatif. } \\
\text { 4. Biaya promosi wisata lebih terjangkau dengan media } \\
\text { sosial. } \\
\text { Kelemahan } \\
\text { 1. Masyarakat belum banyak paham pemasaran digital yang } \\
\text { diterapkan di tingkat pemerintah daerah. } \\
\text { 2. Wisatawan yang mengunjungi iklan dari sosial media } \\
\text { pemerintah kota relatif sedikit, masih perlu ditingkatkan. } \\
\text { 3. Sistem digital masih belum bisa menjangkau semua } \\
\text { kalangan usia dan kelas ekonomi masyarakat. } \\
\text { 4. Kurangnya Sumber Daya Manusia (SDM) yang fokus } \\
\text { menganalisis capaian sistem pemasaran digital pariwisata. }\end{array}$ \\
\hline $\mathbf{F a}$ & $\begin{array}{l}\text { Peluang } \\
\text { 1. Jangkauan promosi digital yang semakin luas lintas daerah } \\
\text { ke depan. } \\
\text { 2. Meningkatnya minat kunjungan wisatawan. } \\
\text { 3. Tingginya pengguna media sosial. } \\
\text { 4. Semakin beragam dan berkembang fitur dari aplikasi media } \\
\text { sosial. } \\
\text { Ancaman } \\
\text { 1. Tingginya persaingan dan minat pemerintah daerah lain } \\
\text { mengembangkan sistem promosi digital. } \\
\text { 2. Perkembangan destinasi baru daerah sekitar yang semakin } \\
\text { cepat. } \\
\text { 3. Minat masyarakat yang mudah berubah dalam } \\
\text { menggunakan platform media sosial. } \\
\text { 4. Kebijakan sepihak perusahaan platform media sosial dalam } \\
\text { perhitungan penonton konten yang berubah sewaktu-waktu. }\end{array}$ \\
\hline
\end{tabular}




\section{HASIL DAN PEMBAHASAN}

\section{A. Hasil Penelitian Analisis Deskriptif}

a) Pengelolaan Sistem Promosi Digital Pemerintah Kota Surakarta

Berbagai upaya promosi dengan bentuk digital selalu diupayakan pengembangannya oleh Pemerintah Kota Surakarta melalui Diskominfo SP (Dinas Komunikasi Informatika Statistik dan Persandian). Diskominfo SP mengembangkan banyak platform untuk mendistribusikan konten Batik Solo TV. Pengembangan yang dimulai dari setiap kelurahan hingga menggunakan media sosial.

... beberapa hal yang sudah dilakukan Pemerintah Kota Surakarta dalam promosi digital memang kita bangun Instagram, kemudian Facebook, Twitter, dan menyasar pada wilayah atau kelurahan kita ada juga ada Batik Solo TV (Wawancara Kepala Dinas Diskominfo SP, pengembangan BSTv).

Pengembangan diupayakan dengan berbagai cara tidak hanya melalui media sosial akan tetapi, juga ditempuh melalui website resmi dari pemerintah kota. Hal tersebut dilakukan agar mempermudah masyarakat mengakses informasi terkait Batik Solo TV yang memuat informasi pariwisata. Pengembangan juga dilakukan dari pihak internal Batik Solo TV dengan memperkuat kerja sama antar-Organisasi Perangkat Daerah (OPD) dan tampilan Batik Solo TV sendiri hingga kerja sama dengan pihak ketiga dalam proses pembuatan konten.

b) Kerja sama Batik Solo TV dengan Pengelola Event

1. Kerja sama Solo Batik Karnival (SBC)

SBC merupakan salah satu acara yang sudah menjadi agenda event kebudayaan kota dan masuk dalam 100 Wonderful Event Indonesia yang dirilis oleh Kemenpar (Kementerian Pariwisata). Dokumentasi acara SBC ini selalu masuk dalam konten promosi digital Solo Batik TV. Hubungan kerja sama dengan Pemerintah Kota Surakarta sudah dibentuk sejak awal berlangsungnya SBC, namun kerja sama terkait penayangan dalam konten digital Solo Batik TV, pihak pengelola dalam hal ini tidak detail hanya otomatis berjalan. Susanto mengungkapkan hal tersebut saat wawancara.

... kalau yang dilakukan oleh kita-kita aja baru tahu kalau ada Balik a Batik Solo TV ini baru aja. Jadi kita tidak pernah secara khusus untuk apa melakukan artinya melakukan kerja sama dengan Batik Solo TV untuk mempromosikan event ini. Jadi memang inisiatifnya dari Batik Solo aja bukan a kita tidak ada inisiatif malahan. Karena ini event yang a event tahunan kota dan juga tahun ini kan a masuk 100 Wonderfull Event Indonesia (Wawancara Ketua SBC).

2. Kerja sama dengan Solo International Performing Art (SIPA)

Pihak pengelola SIPA memaparkan proses kerja sama dengan Diskominfo SP berlangsung dengan kepala dinas tidak spesifik ke bagian pelaksana BSTV terkait konten promosi. 
... Kami sendiri juga melakukan $a$ publikasi sendiri tapi Kominfo dengan apa yang mereka miliki mereka mendukung setiap tahun a pemberitaan tentang SIPA, sebelum SIPA, pas SIPA, dan pasca SIPA itu $a$ selalu mendukung. Kami secara langsung dengan Batik Solo TV itu tidak ada kerja sama jadi kita kerja samanya dengan Dinas Kominfo itu (Wawancara Ketua SIPA).

3. Kerja sama dengan Solo Batik Fashion (SBF)

Pihak pengelola dalam mempublikasi kegiatan SBF ini menjalin kerja sama yang baik dengan wartawan media massa. Kerja sama dibangun dengan menggelar press conference sebelum acara berlangsung. Kerja sama mendetail hingga promosi, belum ada kerja sama khusus dengan dinas terkait. Kerja sama dilakukan secara global dengan Pemerintah Kota Surakarta. Djongko Raharjo memaparkan selama tujuh kali event memimpin, belum ada kerja sama khusus dengan sistem promosi pariwisata online yang dikembangkan Pemerintah Kota melalui BSTv.

...aa kalau itu saya kurang jelas ya selama ini hanya menyediakan materi ya. Cuma kalau masalah kontrak enggak mereka ini sendiri kok mereka a. Iya, dan itu tidak hanya di Solo Batik Fashion saja tapi semua event-event Solo mereka punya itu. Jadi mereka juga bikin untuk kontennya mereka gitu lho dan itu saya juga yakin gak ada kontraknya dengan misalnya SIPA, Solo Batik Karnival atau lainnya enggak lah (Wawancara Ketua SBF).

c) Respons Followers terhadap Konten BSTv

1. Followers Sudah Berkeluarga (FSB)

Salah satu sampel follower yang aktif dalam mengakses informasi melalui BSTv yang sudah berkeluarga adalah Indah Septyaning. Wanita berusia 35 tahun ini mengakses informasi terkait pemerintah kota melalui BSTv hampir setiap hari.

Sebagai follower yang aktif berkunjung ke akun Instagram Pemerintah Kota ini memaparkan selain tayangan video, BSTv juga memuat semua kegiatan Pemerintah Kota Surakarta. Perempuan yang sudah memiliki dua anak ini selain aktif mengakses informasi, juga sering menyebarkan konten tayangan BSTv.

...tindakannya ya, tindakannya saya biasanya aa repost, repost kegiatannya itu terutama yang berkaitan dengan event-event soalnya biasanya aa untuk sekaligus mempromosikan aa ke temen-temen atau warga saya sendiri. Biasanya kalau ada aa kegiatan yang baik saya like kalau enggak hahaha gak saya like. Saya gak aa jarang-jarang banget untuk memberi komentar (Wawancara FSB).

Respons dukungan follower yang sudah berkeluarga lebih banyak pada memilih tanda like dan tidak sampai menulis di kolom komentar. Tindakan untuk mendukung penyebaran konten follower yang sudah berkeluarga lebih kepada repost konten tayangan di akun pribadinya. 


\section{Followers Belum Berkeluarga (FBB)}

Nicolaus Irawan adalah anak muda yang banyak beraktivitas di Kota Surakarta yang memanfaatkan BSTv untuk menggali informasi terkait kegiatankegiatan Kota Surakarta. Nicolaus Irawan adalah salah satu pemuda asal Kota Bengawan yang sering mengikuti event yang digelar di Kota Surakarta.

Sebagai follower yang belum berkeluarga, Nicolaus Irawan, memaparkan ikut bangga Surakarta mau berbenah. Pemerintah Kota Surakarta merespons perkembangan digital. Pemerintah Kota dapat memanfaatkan peluang memasarkan potensi daerah melalui sistem promosi digital dengan platform media sosial.

...mungkin kita seneng ya karena Solo lebih berbenah diri, dia juga bisa melakukan untuk apa memberikan promosi online otomatis tidak hanya orang Solo yang bisa ngliat tapi juga orang-orang luar. Jadi, responsnya bagi kita followers ini oo ternyata ada ya di Solo, jadi kita ikut bangga juga (Wawancara FBB).

Menyikapi langkah Pemerintah Kota Surakarta yang mengembangkan sistem promosi digital ini follower yang belum berkeluarga mempunyai peluang tinggi menyampaikan informasi dengan teman jejaringnya melalui word of mouth (WOM) atau electronic word of mouth (e-worm).

\section{B. Hasil Analisis SWOT}

\section{a) Hasil Matriks SWOT}

Setelah diidentifikasi hasil dari faktor eksternal dan internal, kemudian diolah ke dalam diagram analisis SWOT. Berikut gambaran dari tahapan pencocokan yang digunakan pada Matriks SWOT.

1. Hasil Matriks Internal Factor Evaluation (IFE)

\section{Tabel 2. Hasil Analisis Matrik IFE Organisasi Batik Solo TV}

\begin{tabular}{|c|c|c|c|c|}
\hline & Faktor Internal & Bobot & Peringkat & Nilai \\
\hline \multicolumn{5}{|c|}{ Kekuatan } \\
\hline 1. & $\begin{array}{l}\text { Pemerintah Kota Surakarta yang mengembangkan } \\
\text { sistem pemasaran digital untuk pariwisata tingkat } \\
\text { pemerintah daerah. }\end{array}$ & 0,124 & 2,375 & 0,295 \\
\hline 2. & $\begin{array}{l}\text { Pemasaran digital pariwisata dengan media sosial } \\
\text { mempermudah akses informasi untuk masyarakat. }\end{array}$ & 0,112 & 2,125 & 0,238 \\
\hline 3. & $\begin{array}{l}\text { Keunikan konten dalam bentuk audio visual } \\
\text { melaui video kreatif. }\end{array}$ & 0,133 & 2,750 & 0,366 \\
\hline 4. & $\begin{array}{l}\text { Biaya promosi wisata lebih terjangkau dengan } \\
\text { media sosial. }\end{array}$ & 0,149 & 3,000 & 0,447 \\
\hline
\end{tabular}

Total Nilai Kekuatan $\quad 1,346$

\section{Kelemahan}

1. Masyarakat belum banyak paham pemaparan

$0,145 \quad 2,125 \quad 0,308$
digital yang diterapkan di tingkat pemerintah daerah.

2. Wisatawan yang mengunjungi iklan dari sosial media pemerintah kota relatif sedikit, masih perlu

$0,115 \quad 2,625 \quad 0,302$
ditingkatkan. 
3. Sistem digital masih belum bisa menjangkau $\quad 0,103 \quad 2,875 \quad 0,296$ semua kalangan usia dan kelas ekonomi masyarakat.

4. Kurangnya Sumber Daya Manusia (SDM) yang fokus menganalisis capaian sistem pemasaran digital pariwisata.

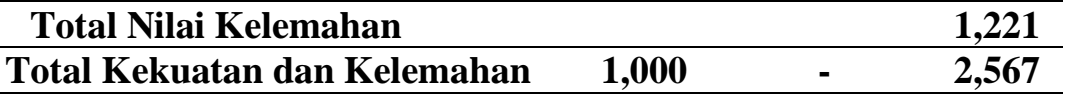

Pada Tabel 2, hasil analisis matrik IFE nilai tertinggi adalah "Biaya promosi wisata lebih terjangkau dengan media sosial” dengan angka 0,447, sedangkan yang terendah adalah "Sistem digital masih belum bisa menjangkau semua kalangan usia dan kelas ekonomi masyarakat” dengan angka 0,296.

2. Hasil Matriks External Factor Evaluation (EFE)

Tabel 3. Hasil Analisis Matrik EFE Organisasi Batik Solo TV

\begin{tabular}{|c|c|c|c|c|}
\hline & Faktor Eksternal & Bobot & Peringkat & Nilai \\
\hline \multicolumn{5}{|c|}{ Peluang } \\
\hline 1. & $\begin{array}{l}\text { Jangkauan promosi digital yang semakin luas } \\
\text { lintas daerah ke depan. }\end{array}$ & 0,163 & 3,750 & 0,611 \\
\hline 2. & Meningkatnya minat kunjungan wisatawan. & 0,142 & 3,375 & 0,479 \\
\hline 3. & Tingginya pengguna media sosial. & 0,165 & 4,000 & 0,660 \\
\hline 4. & $\begin{array}{l}\text { Semakin beragam dan berkembang fitur dari } \\
\text { aplikasi media sosial. }\end{array}$ & 0,165 & 4,000 & 0,660 \\
\hline & & \multicolumn{2}{|c|}{ Total Nilai Peluang } & 2,410 \\
\hline \multicolumn{5}{|c|}{ Ancaman } \\
\hline 1 & $\begin{array}{l}\text { Tingginya persaingan dan minat pemerintah } \\
\text { daerah lain mengembangkan sistem pemasaran } \\
\text { digital. }\end{array}$ & 0,082 & 3,875 & 0,318 \\
\hline 2 & $\begin{array}{l}\text { Perkembangan destinasi baru daerah sekitar yang } \\
\text { semakin cepat. }\end{array}$ & 0,098 & 3,500 & 0,343 \\
\hline 3 & $\begin{array}{l}\text { Minat masyarakat yang mudah berubah } \\
\text { dalam menggunakan platform media sosial. }\end{array}$ & 0,087 & 3,625 & $\mathbf{0 , 3 1 5}$ \\
\hline 4 & $\begin{array}{l}\text { Kebijakan sepihak perusahaan platform media } \\
\text { sosial dalam perhitungan penonton konten yang } \\
\text { berubah sewaktu-waktu. }\end{array}$ & 0,097 & 3,375 & 0,327 \\
\hline \multicolumn{2}{|c|}{ Total Nilai Ancaman } & & & 1,303 \\
\hline \multicolumn{2}{|c|}{ Total Peluang dan Ancaman } & 1,000 & - & 3,713 \\
\hline
\end{tabular}

Pada Tabel 3, hasil analisis matrik EFE nilai tertinggi adalah "Tingginya pengguna media sosial" dan "Semakin beragam dan berkembang fitur dari aplikasi media sosial" dengan angka 0,660, sedangkan yang terendah adalah "Minat masyarakat yang mudah berubah dalam menggunakan platform media sosial” dengan angka 0,315 . 


\section{b) Tahap Pencocokan}

\section{Analisis Matriks IE (Internal-Eksternal)}

Tahap ini merupakan tahap pencocokan dengan memasukkan hasil pembobotan dan peringkat pada Matriks EFE dan IFE ke dalam Matriks IE. Total nilai tertimbang pada Matriks EFE dan IFE akan berada pada kisaran 1,0 (terendah) hingga 4,0 (tertinggi), dengan nilai rata-rata 2,5. Dari hasil perhitungan di atas, diperoleh hasil IFE sebesar 2,567 dan EFE sebesar 3,713. Angka tersebut selanjutnya dapat menggambarkan posisi Organisasi Batik Solo TV melalui Matriks IE.

\begin{tabular}{|c|c|c|c|c|}
\hline \multirow{5}{*}{ 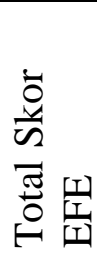 } & \multicolumn{4}{|c|}{ Total Skor IFE } \\
\hline & 4.0 & 3.0 & 2.0 & 1.0 \\
\hline & 3.0 & $\mathrm{I}$ & II & III \\
\hline & 2.0 & IV & $\mathrm{V}$ & VI \\
\hline & 1.0 & VII & VIII & IX \\
\hline
\end{tabular}

Gambar 1. Matriks IE Organisasi Batik Solo TV

Posisi Organisasi Batik Solo TV melalui Matriks IE menunjukkan Growth and Build (tumbuh dan bina) karena berada pada posisi I. Strategi yang cocok adalah intensif (penetrasi pasar, pengembangan pasar, dan pengembangan produk) atau integrasi (integrasi ke belakang, integrasi ke depan, dan integrasi horizontal).

2. Kuadran Analisis SWOT

Untuk kuadran analisis SWOT Batik Solo TV dihitung berdasarkan berikut:

Nilai Faktor Internal $=$ Kekuatan - Kelemahan

$$
\begin{aligned}
& =1,346-1,221 \\
& =0,125
\end{aligned}
$$

Nilai Faktor Eksternal = Peluang - Ancaman

$$
\begin{aligned}
& =2,410-1,303 \\
& =1,107
\end{aligned}
$$

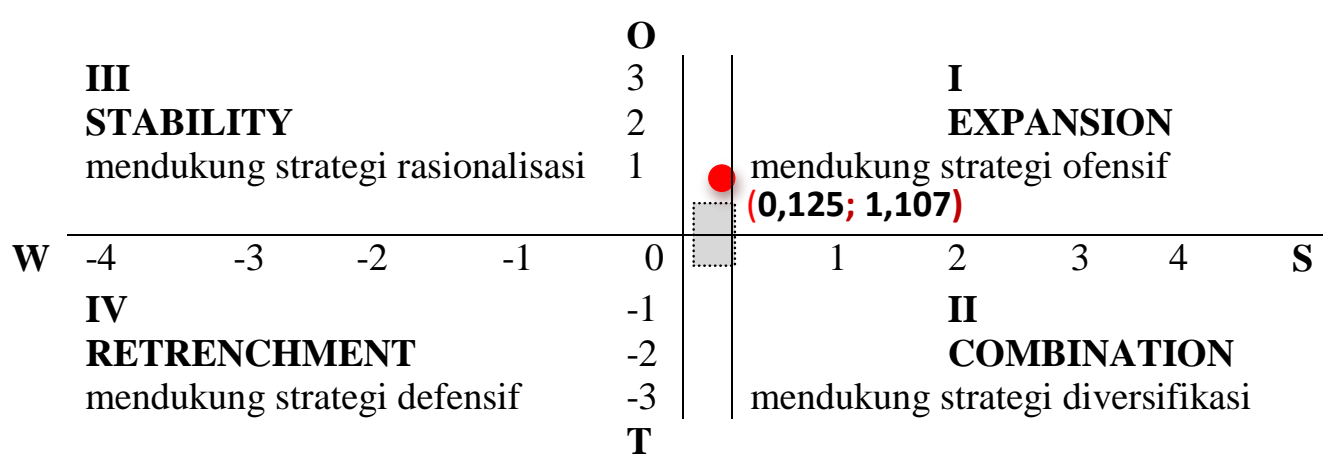

Gambar 2. Kuadran Analisis SWOT Solo Batik TV 
Kuadran Analisis SWOT Batik Solo TV menunjukkan posisinya berada pada kuadran I yaitu EXPANSION. Ini merupakan situasi yang sangat menguntungkan. Organisasi tersebut memiliki peluang dan kekuatan sehingga dapat memanfaatkan peluang yang ada. Strategi pemasaran yang diterapkan dalam kondisi ini adalah strategi yang mendukung kebijakan pertumbuhan yang agresif (GROWTH ORIENTED STRATEGY), tetapi dalam melakukan analisis lebih lanjut diperlukan pemilihan strategi berupa penggunaan setiap kekuatan untuk menghadapi setiap ancaman dengan menciptakan diversifikasi untuk menciptakan peluang. Selanjutnya adalah perumusan strategi-strategi melalui Matriks SWOT yang diperoleh dengan memasangkan faktor-faktor eksternal dengan faktor-faktor internal. Pada Matriks SWOT diperlihatkan kesesuaian antara kekuatan, kelemahan, peluang, dan ancaman.

\section{Matriks SWOT}

Matriks SWOT diperoleh dengan memasangkan faktor-faktor eksternal dengan faktor-faktor internal. Pada Matriks SWOT diperlihatkan kesesuaian antara kekuatan, kelemahan, peluang, dan ancaman seperti terlihat pada tabel.

Berdasarkan hasil kuadran Analisis SWOT Organisasi Batik Solo TV menunjukkan posisi pada kuadran I yaitu Expansion. Ini merupakan situasi yang sangat menguntungkan. Organisasi tersebut memiliki peluang dan kekuatan sehingga dapat memanfaatkan peluang yang ada. Selanjutnya perlu dirumuskan alternatif-alternatif strategi menggunakan Matriks SWOT untuk mendukung keputusan dari hasil analisis kuadran SWOT. Perumusan strategi-strategi melalui Matriks SWOT adalah sebagai berikut.

Tabel 4. Alternatif Strategi Organisasi Batik Solo TV dalam Matriks SWOT

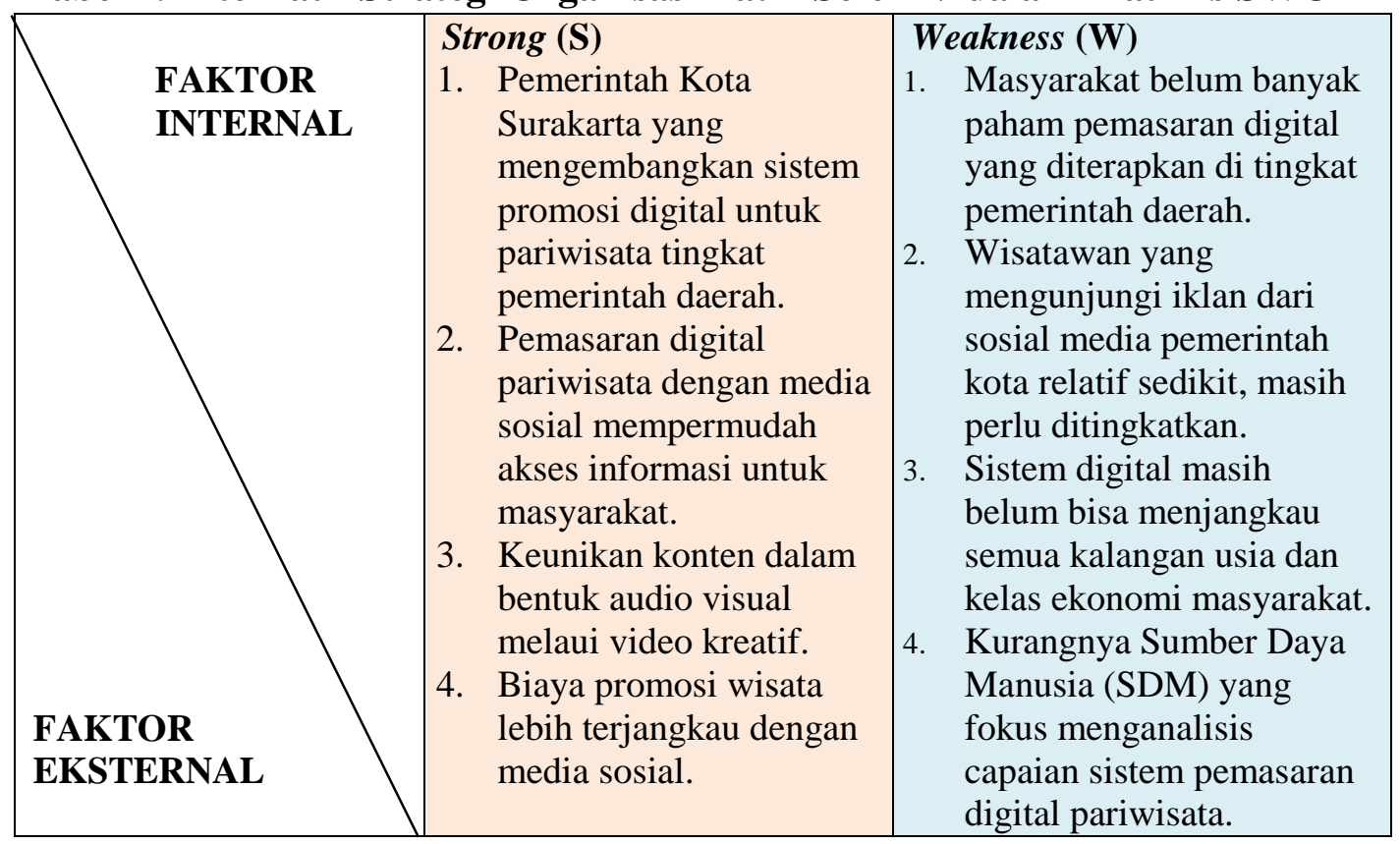




\begin{tabular}{|c|c|c|}
\hline 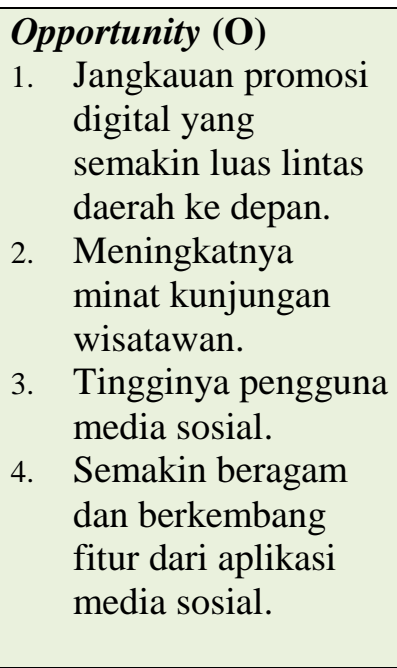 & $\begin{array}{l}\text { SO } \\
\text { 1. Mendistribusikan konten } \\
\text { pemasaran berkualitas } \\
\text { dengan lebih gencar, } \\
\text { berkelanjutan dengan } \\
\text { menggunakan berbagai } \\
\text { platform media sosial. } \\
\text { (S1, S2, S3, O1, O2) } \\
\text { 2. Menggunakan rencana } \\
\text { kerja yang matang dan } \\
\text { terstruktur serta link } \\
\text { kerja sama guna } \\
\text { meningkatkan promosi } \\
\text { melalui media sosial. } \\
\text { (S5, O3, O4) }\end{array}$ & $\begin{array}{l}\text { WO } \\
\text { 1. Menyediakan SDM } \\
\text { pengawas dan pengelola } \\
\text { konten profesional untuk } \\
\text { memonitor proses produksi } \\
\text { dan distribusi untuk } \\
\text { menjangkau viewers lebih } \\
\text { luas. (W1, W2, W3, O1, } \\
\text { O2) } \\
\text { 2. Memiliki strategi alokasi } \\
\text { SDM yang paham analisis } \\
\text { data viewers dan algoritma, } \\
\text { melihat peluang pengguna } \\
\text { media sosial terus } \\
\text { meningkat. (W4, O3, O4) }\end{array}$ \\
\hline $\begin{array}{l}\text { Threat (T) } \\
\text { 1. } \text { Tingginya } \\
\text { persaingan dan } \\
\text { minat pemerintah } \\
\text { daerah lain } \\
\text { mengembangkan } \\
\text { sistem pemasaran } \\
\text { digital. } \\
\text { 2. Perkembangan } \\
\text { destinasi baru daerah } \\
\text { sekitar yang semakin } \\
\text { cepat. } \\
\text { Minat masyarakat } \\
\text { yang mudah berubah } \\
\text { dalam menggunakan } \\
\text { platform media } \\
\text { sosial. } \\
\text { Kebijakan sepihak } \\
\text { perusahaan platform } \\
\text { media sosial dalam } \\
\text { perhitungan } \\
\text { penonton konten } \\
\text { yang berubah } \\
\text { sewaktu-waktu. }\end{array}$ & $\begin{array}{l}\text { ST } \\
\text { 1. Menambah ragam jenis } \\
\text { konten berkualitas dan } \\
\text { jaringan kerja sama } \\
\text { dengan pelaku pariwisata } \\
\text { kota. (S1, S3, T1, T2) } \\
\text { 2. Meningkatkan pelayanan } \\
\text { dan respons admin media } \\
\text { sosial untuk } \\
\text { meningkatkan } \\
\text { engagement (keterlibatan). } \\
\text { (S2, T3) } \\
\text { 3. Membangun komunikasi } \\
\text { dan perjanjian dengan } \\
\text { para pihak yang bekerja } \\
\text { sama. (S4, T4) }\end{array}$ & $\begin{array}{l}\text { WT } \\
\text { 1. Perlu perubahan tatanan } \\
\text { sistem organisasi dalam } \\
\text { operasional dan produksi. } \\
\text { (W1, W2, W3, W4, T1, T2, } \\
\text { T3, T4) }\end{array}$ \\
\hline
\end{tabular}

\section{c) Tahap Keputusan}

1. Hasil Matriks SWOT memberikan beberapa alternatif strategi, yaitu:

SO : 1. Mendistribusikan konten pemasaran berkualitas dengan lebih gencar, berkelanjutan dengan menggunakan berbagai platform media sosial. (S1, S2, S3, O1, O2) 
2. Menggunakan rencana kerja yang matang dan terstruktur serta link kerja sama guna meningkatkan promosi melalui media sosial. (S5, O3, O4)

WO : 1. Menyediakan SDM pengawas dan pengelola konten profesional untuk memonitor proses produksi dan distribusi untuk menjangkau viewers lebih luas. (W1, W2, W3, O1, O2)

2. Memiliki strategi alokasi SDM yang paham analisis data viewers dan algoritma, melihat peluang pengguna media sosial terus meningkat. (W4, O3, O4)

ST : 1. Menambah ragam jenis konten berkualitas dan jaringan kerja sama dengan pelaku pariwisata kota. (S1, S3, T1, T2)

2. Meningkatkan pelayanan dan respons admin media sosial untuk meningkatkan engagement (keterlibatan). (S2, T3)

3. Membangun komunikasi dan perjanjian dengan para pihak yang bekerja sama. (S4, T4)

WT : 1. Perlu perubahan tatanan sistem organisasi dalam operasional dan produksi. (W1, W2, W3, W4, T1, T2, T3, T4)

2. Tahap Keputusan Berdasarkan Matriks IE

Posisi organisasi Batik Solo TV melalui Matriks IE menunjukkan

Expansion karena berada pada posisi I. Strategi yang cocok adalah intensif (penetrasi pasar, pengembangan pasar, dan pengembangan produk dalam hal ini konten) atau integrasi (integrasi ke belakang, integrasi ke depan, dan integrasi horizontal).

a) Intensif

- Penetrasi Pasar: Memasarkan dengan gencar garapan konten video kreatif dengan menggunakan berbagai platform media sosial.

- Pengembangan Pasar: Menambah dan memperluas jaringan kerja sama serta meningkatkan jumlah SDM (konten strategi dan tim produksi) untuk membuka jaringan promosi digital yang lebih luas.

- Pengembangan Produk: Meningkatkan ide dan konsep garapan video kreatif serta meningkatkan respons untuk membangun engagement (interaksi dengan followers).

b) Integrasi

Untuk integrasi strategi yang digunakan adalah integrasi ke belakang yaitu memiliki kontrol dan pengawasan atas garapan konten video kreatif untuk memberikan jaminan kepuasan informasi dan tampilan tayangan bagi followers. Dari alternatif strategi Matriks SWOT ini memang belum dilakukan dan diterapkan oleh Batik Solo TV maka, strategi ini masih relevan untuk diterapkan pada Batik Solo TV. 
3. Tahap Keputusan Berdasarkan Kuadran Analisis SWOT

Kuadran Analisis SWOT Batik Solo TV menunjukkan posisi yang berada pada kuadran I Expansion sehingga diperlukan pemilihan strategi yang berupa penggunaan setiap Kekuatan untuk menghadapi setiap Ancaman. Posisi tersebut mengarah pada strategi SO dan WO yaitu perbaikan rencana kerja, distribusi konten lebih gencar, alokasi SDM profesional, untuk menghadapi persaingan sistem pemasaran digital lain. Dalam hal ini adalah pemerintah daerah yang juga mulai mengembangkan sistem promosi digital.

\section{TEMUAN}

Penelitian sistem promosi digital yang dikembangkan Pemerintah Kota Surakarta melalui Batik Solo TV (BSTv), menemukan pengelolaan BSTv dipegang oleh Diskominfo SP. Dalam proses produksi konten Diskominfo SP menggandeng pihak ketiga untuk membantu produksi konten yang khusus. Hal tersebut dilakukan sebagai salah satu upaya memperbaiki kualitas tayangan konten agar lebih menarik.

Produksi konten BSTv dalam mempromosikan event-event yang digelar di Kota Solo kurang melibatkan pengelola event. Hal itu berdampak pada belum adanya integrasi antara sistem promosi digital yang dikembangkan masing-masing pengelola event dengan sistem promosi digital yang dikembangkan Pemerintah Kota melalui BSTv.

Masih minimnya koordinasi pengelola BSTv dengan pengelola event ini memberikan dampak terhadap kurang beragamnya konten yang dapat diangkat dari satu event yang digelar. Pengelola event belum bisa memanfaatkan secara maksimal keberadaan BSTv. Hal tersebut terbukti dengan temuan dari pernyataan pengelola event yang menyatakan belum adanya tawaran kerja sama dengan BSTv untuk mempromosikan. Selama ini pengelola event masih ditawarkan sistem promosi konvensional oleh dinas terkait saat rapat koordinasi.

Selanjutnya, posisi pengembangan sistem promosi online BSTv berada pada kuadran I, yaitu expansion (mendukung strategi agresif). Ini merupakan kondisi yang sangat menguntungkan bagi BSTv. BSTv memiliki peluang dan kekuatan sehingga dapat memanfaatkan peluang yang ada. Strategi pemasaran yang diterapkan dalam kondisi ini adalah strategi yang mendukung kebijakan pertumbuhan yang agresif (GROWTH ORIENTED STRATEGY), sehingga diperlukan pemilihan strategi menggunakan kekuatan dan memanfaatkan peluang untuk menghadapi ancaman. Posisi tersebut mengarah kepada strategi SO dan WO, yaitu:

1. Mendistribusikan konten pemasaran berkualitas dengan lebih gencar, berkelanjutan dengan menggunakan berbagai platform media sosial. ( $\mathrm{S} 1$, $\mathrm{S} 2, \mathrm{~S} 3, \mathrm{O} 1, \mathrm{O} 2)$ 
2. Menggunakan rencana kerja yang matang dan terstruktur serta link kerja sama guna meningkatkan promosi melalui media sosial. (S5, O3, O4)

3. Menyediakan SDM pengawas dan pengelola konten profesional untuk memonitor proses produksi dan distribusi untuk menjangkau viewers lebih luas. (W1, W2, W3, O1, O2)

4. Memiliki strategi alokasi SDM yang paham analisis data viewers dan algoritma, melihat peluang pengguna media sosial terus meningkat. (W4, $\mathrm{O} 3, \mathrm{O} 4)$

Berdasarkan analisis faktor IFE dan EFE diperoleh interval faktor internal dengan kuadran analisis SWOT sebesar $\mathbf{0 , 1 2 5}$ dan interval faktor eksternal sebesar 1,107. Kuadran analisis SWOT pengembangan sistem promosi digital BSTv berada pada posisi kuadran I yaitu expansion, dalam posisi ini seyogyanya pengelola BSTV menentukan strategi menggunakan kekuatan dan memanfaatkan peluang dengan terus memperhatikan respons masyarakat terhadap BSTv.

Mempromosikan potensi budaya daerah seiring perkembangan zaman harus menyesuaikan dengan sistem komunikasi bermedia masyarakat. Pengelola harus mampu beradaptasi dengan memudahkan masyarakat mengakses informasi pariwisata budaya dengan tayangan audio visual melalui media sosial. David J. Crowley dan David Mitchell memaparkan, komunikasi bermedia atau interaksi bermedia mengacu kepada komunikasi yang dilakukan dengan menggunakan teknologi komunikasi dan informasi yang bersifat hi-tech dan sangat berbeda dengan komunikasi tatap muka. Berbeda dengan komunikasi tatap muka, komunikasi bermedia menggabungkan beberapa arti dengan menyalurkan petunjuk melalui simbol secara tersendiri. Komputerisasi media seperti telepon dan layanan pesan singkat, memudahkan untuk menyalurkan bentuk lisan dan simbol-simbol nonverbal daripada perangkat generasi terdahulu (Timothy G., et.al., 2012).

Pengembangan Batik Solo TV yang dilakukan pemerintah Kota Surakarta merupakan langkah strategis untuk mengembangkan komunikasi bermedia berbasis hi-tech dan mendekatkan informasi tentang potensi budaya dan pariwisata daerah kepada masyarakat langsung melalui media sosial yang mudah diakses setiap saat. Hal tersebut akan berdampak kepada kemajuan kebudayaan dan potensi daerah karena mempercepat proses penyebaran informasi secara langsung kepada masyarakat.

\section{SARAN}

1. Pengelola perlu mengembangkan kemampuan SDM yang fokus mengolah data capaian viewers media sosial untuk mengontrol respons masyarakat terhadap konten tayangan BSTv. 
2. Selalu menggali potensi baru dari Kota Surakarta untuk materi konten yang lebih menarik sehingga mampu meningkatkan minat viewers merespons konten BSTv untuk meningkatkan engagement.

3. Meningkatkan komunikasi dan kerja sama dengan pengelola event kebudayaan agar sistem promosi dapat saling terintegrasi.

4. Meningkatkan kontrol sistem distribusi konten visual dengan search engine optimization (SEO).

\section{IMPLIKASI MANAJERIAL}

1. Menerapkan sistem search engine optimization (SEO) dalam setiap platform media sosial untuk mendistribusikan konten promosi BSTV.

2. Meningkatkan respons admin media sosial untuk menjalin hubungan dengan masyarakat atau viewers yang akan meningkatkan jumlah pengunjung konten.

3. Dalam produksi konten mengikuti perkembangan konsep konten kreatif yang diminati masyarakat.

4. Memaksimalkan fasilitas yang tersedia dalam setiap platform media sosial.

\section{KEPUSTAKAAN}

Damanik, P. J. (2013). Pariwisata Indonesia: Antara Peluang dan Tantangan. Yogyakarta: Pustaka Pelajar.

David, F. R. (2006). Manajemen Strategis (10th ed.). Jakarta: Salemba Empat.

David, De Cremer; Dick, Rolf van; Murnighan, J. K. (2011). Social Psychology and Organizations. New York London: Taylor \& Francis e-Library.

Kotler, P. ; \& K. L. K. (2012). Marketing Management (14th ed.). New Jersey: Prentice-Hall Published.

Peter, J. Paul ; Donnelly, Jr., J. H. (2011). A Preface to Marketing Management (12th ed.). New York: Mc Graw Hill.

Ramly, N. (2007). Pariwisata berwawasan lingkungan: belajar dari kawasan wisata Ancol. Jakarta: Grafindo Khazanah Ilmu.

Rangkuti, F. (1997). Teknik Membedah Kasus Bisnis Analisis SWOT Cara Perhitungan Bobot, Rating, dan OCAI. Jakarta: Gramedia Pustaka Utama.

Rangkuti, F. (2016). Teknik Membedah Kasus Bisnis Analisis SWOT Cara Perhitungan Bobot, Rating, dan OCAI. Jakarta: Gramedia Pustaka Utama.

Pearce II, John A. ; \& Robinson Jr, R. B. (2008). Manajemen Strategis Formulasi, Implementasi, dan Pengendalian. Jakarta: Salemba Empat.

Sugiyono. (2013). Metode Penelitian Kuantitatif, Kualitatif, dan R\&D. Bandung: Alfabeta.

Sutopo, H. B. (2006). Metodologi Penelitian Kualitatif: Dasar Teori dan Terapannya dalam Penelitian. Surakarta: Universitas Sebelas Maret Surakarta. 
Timothy, G. Plax; Waldeck, Jennifer H.; Kearney, P. (2012). Business and Professional Communication in a Digital Age (1st ed.). Cengage Learning.

\section{Webtografi}

Administrator. (2015). Rilis Pers: Hasil Survey "Profil Pengguna Internet di Indonesia 2014" oleh APJII bekerja sama dengan Pusat Kajian Komunikasi Universitas Indonesia. In PUSKAKOM: Pusat Kajian Komunikasi Universitas Indonesia. Retrieved from http://puskakom.ui.ac.id/publikasi/rilis-pers-hasil-survey-profil-penggunainternet-di-indonesia-2014-oleh-apjii-bekerja-sama-dengan-pusat-kajiankomunikasi-universitas-indonesia.html

Bohang, F. K. (2018). Juni 2018, Pengguna Aktif Instagram Tembus 1 Miliar. Retrieved December 5, 2018, from Kompas.com website: https://tekno.kompas.com/read/2018/06/21/10280037/juni-2018pengguna-aktif-instagram-tembus-1-miliar

Wicaksono, B. (2018). Kota Solo Masih Dilirik Wisatawan Mancanegara. Retrieved June 7, 2018, from Jawa Pos: Radar Solo website: https://radar.jawapos.com/radarsolo/read/2018/02/06/46776/kota-solomasih-dilirik-wisatawan-mancanegara

\section{Informan}

Kentis Ratnawati, Kepala Diskominfo Kota Surakarta.

Taufan Redina, Admin Instagram Pemerintah Kota Surakarta.

Susanto, Ketua Komunitas Solo Batik Carnival.

Irawati Kusumorasri, Ketua Komunitas SIPA.

Jongko Raharjo, Solo Batik Fashion.

Wenny Purwanti, Solo City Jazz.

Indah Septyaning, Pengikut Instagram Pemerintah Kota yang sudah berkeluarga.

Nicolaus Irawan, Pengikut Instagram Pemerintah Kota yang belum berkeluarga. 